\title{
Investigation and Analysis on the Explosion Accident in the Mountain Tunnel
}

\author{
Dong $\operatorname{Yan}^{1}$, Qiong $\mathrm{Wu}^{1 *}$, Tengyu $\mathrm{Li}^{2}$ and Yinyin $\operatorname{Ren}^{3}$ \\ ${ }^{1}$ College of Architecture and Civil Engineering, Xinyang Normal University, Xinyang 464000, China \\ ${ }^{2}$ College of Mechanical and Vehicle Engineering, Taiyuan University of Technology, Taiyuan 030000, China \\ Faculty of Engineering, University of New South Wales, Sydney, NSW 2052, Australia
}

Received 4 June 2019; Accepted 12 August 2019

\begin{abstract}
Blasting operation has gradually become an efficient and fast construction method with the rapid development of industrial level. In China, hole drilling smooth blasting method has been widely used in most railway tunnel projects. Therefore, substantial attention should be paid to the safety of tunnel blasting. In order to show the properties of explosive products in limited tunnel spaces and their influence on people, the overpressure damage of shock wave and the effects of heat radiation and harmful gas from explosion were checked by performing theoretical analysis and numerical simulation. This study took the sudden explosive explosion in a tunnel excavation as an example. The accuracy of the calculation and analysis results were verified by on-site investigation. The main cause of the accident and related preventive measures were also discussed. The dangerous range of casualties under different explosive charges in the tunnel was finally achieved by relating the theoretical analysis to the actual circumstance. Results show that the explosion of a large number of detonating fuses in the semi-closed tunnel is equal to the explosion of approximately $200 \mathrm{~kg}$ of TNT. The produced shock wave, thermal radiation, and harmful gas affect the scope of over $400 \mathrm{~m}$ with enormous destruction. The explosive power of a detonator cord should never be underestimated. The large number of casualties in this tunnel explosion accident highlights the importance of safety. This study provides specific reference for determining safety range in a blasting construction, which would also provide great guidance in other tunnel projects.
\end{abstract}

Keywords:Tunnel explosion, Theoretical analysis, Numerical calculation, Overpressure damage, Heat radiation, Harmful gas, Dangerous range of casualties

\section{Introduction}

National transportation has become the foundation of national economic development. The construction of modern transportation facilities has gradually been extended to remote mountainous areas, among which the construction of bridges and tunnels is the top priority. Blasting is an important construction technique in bridge construction and tunneling, which will serve as a dominant method for a long time in the future. At present, tunnel construction has stepped into a stage of rapid development, especially for high-speed railway and expressway. The construction period is urgent with the continuous expansion of the scope of tunnel construction. Several tunnel safety accidents have not only caused casualties and great economic losses but also seriously affected the progress schedule in recent years. Close attention has to be paid to accidents caused by tunnel builders and related technical personnel. To safely and effectively conduct rock excavation, blasting technology and relevant safety issues should be given great importance to promote the sustainable development of the industry and provide strong support for the national basic construction. In the rapid development of blasting engineering, explosion accidents occasionally occur due to various reasons [1]. For individuals, life and health are greatly threatened; for the whole society, an explosion accident is a great destabilizing

*E-mail address: wuqiong180216@163.com

ISSN: 1791-2377 @ 2019 School of Science, IHU. All rights reserved.

doi:10.25103/jestr.124.19 factor [2]. Therefore, substantial attention should be paid to explosion accidents, from which lessons should be learned.

This study investigated the safety accident of an explosive explosion in the tunneling of South Lvliang Mountain and analyzed the casualties by combining theoretical calculation and numerical simulation. This work also focused on several aspects, including overpressure damage, thermal radiation, and harmful gas, which provided evidence for the objective truth of this accident to avoid concealing. This explosion accident indicated that substantial attention should be paid to the safe use of explosives in similar engineering construction. Comprehensive understanding of the cause of the accident should be strengthened, and lessons should be drawn from the accident to effectively prevent the potential safety risks in tunnel construction.

\section{State of the Art}

At present, various studies toward the safety of tunnel explosion have been conducted. Qiushi Yan [3] used dynamic finite element software to numerically simulate the internal explosion effect of a subway tunnel in Beijing. However, the selected total dosage was obviously lower than that used in actual engineering situation. Zhongxian Liu [4] conducted IBIEM modeling of the elastic dynamic response on a lined tunnel under blast loading in saturated poroelastic half space. Le Xie [5] reported simplified analysis and discussion on the safety of lining structure in a rectangular 
channel under top explosion. The analysis was focused on the mechanical properties of the damage of the lining structure and surrounding rock, but it lacked in the dynamic analysis of the internal media of the tunnel. Zhipeng Li [6,7] evaluated the safety and stability of the tunnel structure after disaster. The numerical simulation of explosion was realized by using the created high-efficiency model construction technique for tunnel gas explosion and subsequently proposing the treatment scheme. However, the specific situation of gas explosion in tunnel was limited. Desen Kong $[8,9]$ investigated the propagation law of blast wave in subway tunnels and established the calculation model of shock responses of a metro tunnel through fluid-structure coupling computation. Nevertheless, the relevant thermal field and harmful gas analysis were missing. Following thermal theory of explosive blast wave, Casal [10] and Genova [11] proposed a rapid estimation of the overpressure of expanding vapor to calculate the explosion overpressure and wave velocity. The research was forward looking, but the calculation coefficient still needed further study. Benselama [12] and Uystepruyst [13] proposed two ways of the evolution of blast wave in tunnels and simulated the propagation of subway blast wave in tunnels through numerical calculation. The model test and simulation results were roughly consistent [14]. Smith [15] established a multigroup tunnel model and investigated the effect of tunnel wall roughness on shock wave attenuation. He concluded that the tunnel wall roughness significantly affected shock wave propagation. Wen [16] investigated the propagation law of explosion flame and shockwave through experiments. The relevant characteristics of shockwave and flame were determined considering the number of obstacles, obstacle distance from ignition source, and obstacle positions. Syrunin [17] performed an explosion experiment in a cylindrical explosion-proof container. Subsequently, he presented an anti-explosion checking calculation and an overpressure bearing analysis, which provided reference for the overall analysis of explosion overpressure.

The aforementioned studies were focused on the analysis of the mechanical characteristics of tunnel explosion and the stress properties of tunnel walls. However, the impact of multiple hazard factors from mountain tunnel explosion was seldom reported, especially those that determined the safety area in tunnel blasting. In the present study, a calculation model is established to analyze the propagation of blast wave, the overpressure-distance relationship, the thermal effect of explosion, and the influence of harmful gas based on theoretical analysis and numerical simulation. The model provides the basis for the safety protection in tunnel blasting engineering.

The remainder of this study is organized as follows. Section 3 establishes the explosion mechanical model and proposes the calculation of damage value of the explosion products based on actual engineering examples. Section 4 discusses that the propagation of blast wave, thermal effect, and influence law of harmful gas are obtained through theoretical method and numerical analysis. Section 5 summarizes the conclusions.

\section{Methodology}

\subsection{Project Profile}

The tunnel explosion accident occurred in the railway construction project in south-central Shanxi Province. The entrance of the South Lvliang Mountain tunnel is located at
$\mathrm{Pu}$ county (in Shanxi Province, China), and the exit is located at Hongtong County (in Shanxi Province, China). The tunnel has a double-hole and single-line design. Drilling and blasting methods were used in tunnel excavation. The builders illegally transported a detonating cord with a length of $14000 \mathrm{~m}$, a detonating tube with a length of $4000 \mathrm{~m}$, and other explosives into the tunnel and temporarily placed them near the excavation working face. The detonator cord exploded due to anthropogenic causes in the tunnel, thereby causing eight deaths and five serious injuries [18].

According to the investigation, at approximately $8 \mathrm{~m}$ away from excavation face, the initial lining on both sides of the tunnel was seriously damaged, large areas of the gunite were damaged and fell off, the support steel columns deformed, and the support joint part cracked. The vault and side wall of the tunnel were severely blackened due to the burning of high-temperature and high-pressure gas from the explosion. Figure 1 shows the field situation.

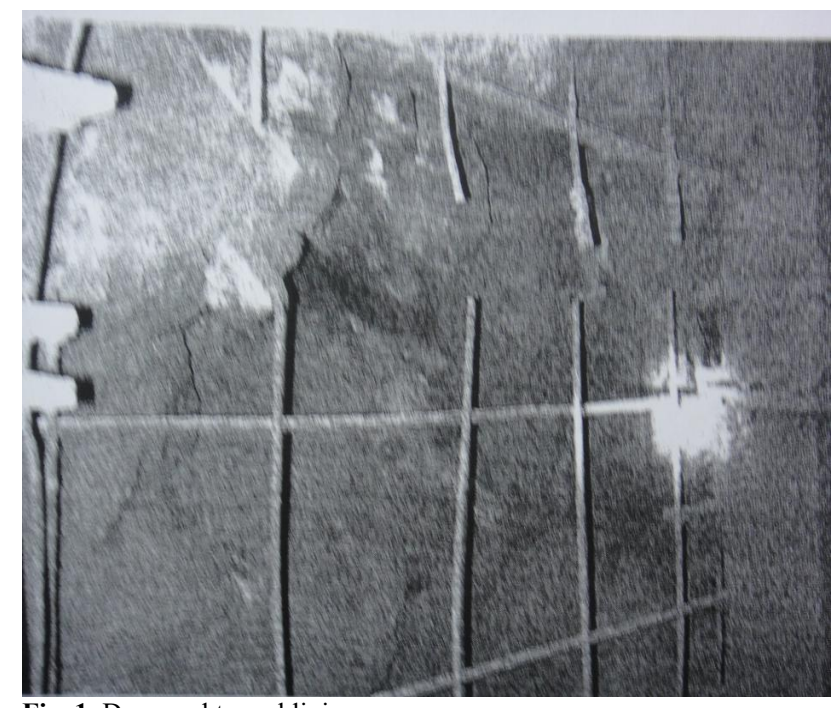

Fig. 1. Damaged tunnel lining

Several holes were found on the ground. Rock wave and detonation products spread to the ground, and they were reflected to generate stretching wave. The earthwork in the explosive center was broken off and thrown around by the stretching wave. The detonation products further destroyed the surface earth, which in turn was accelerated and thrown out of the surface. Blasting craters were formed. The diameter of the largest blasting crater is approximately $1.2 \mathrm{~m}$, and its depth is approximately $0.3 \mathrm{~m}$. Figure 2 shows the site situation of the blasting crater.

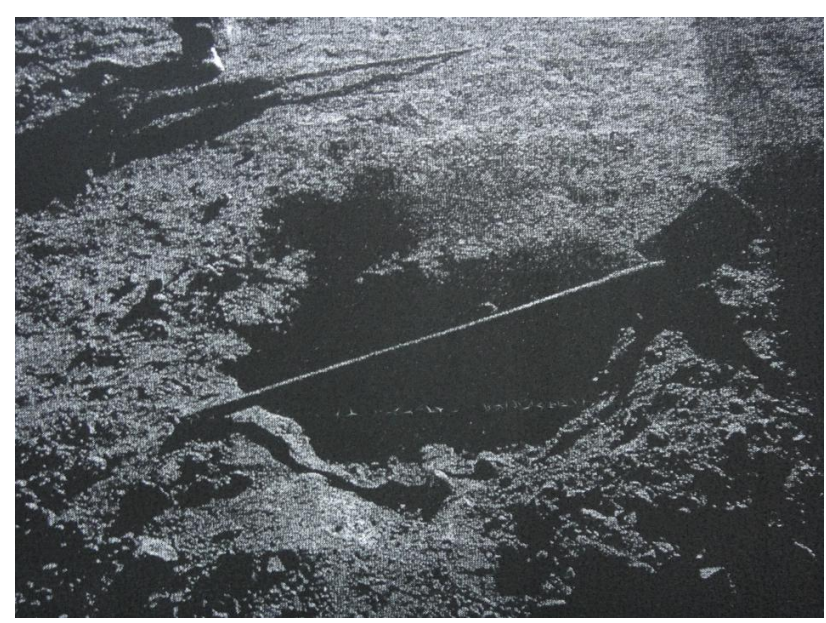

Fig. 2. Damaged tunnel lining 
Figure 3 shows that the fuselage of the tunneling machine at $300 \mathrm{~m}$ away from the tunneling working face is seriously distorted, indicating that the blast wave still has great energy when propagating to this position.

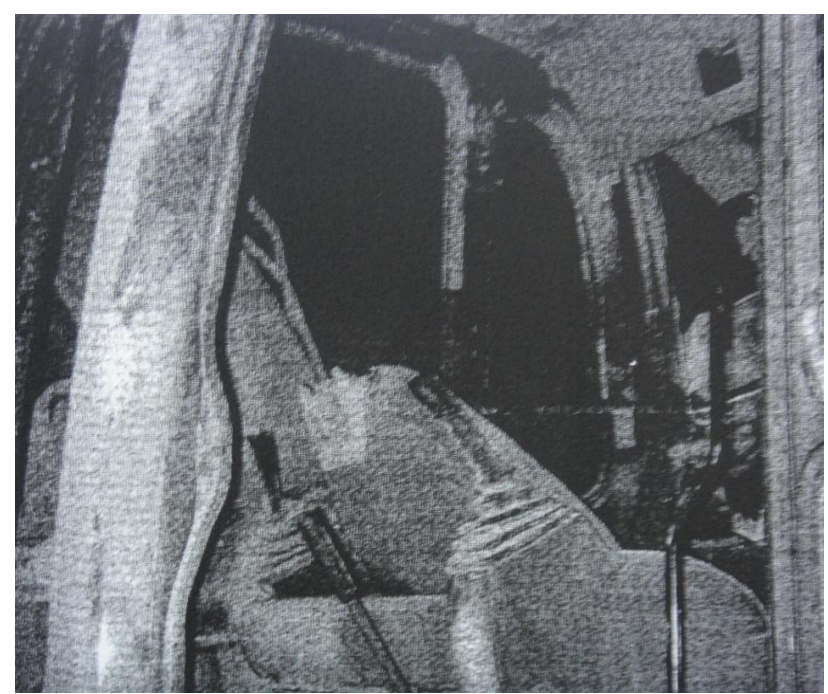

Fig. 3. Tunneling machine with severe damage

A schematic of the explosion site was added (Figure 4) to perform an intuitive analysis on the influence scope of the shock wave and the distribution of specific casualties in this explosion accident.

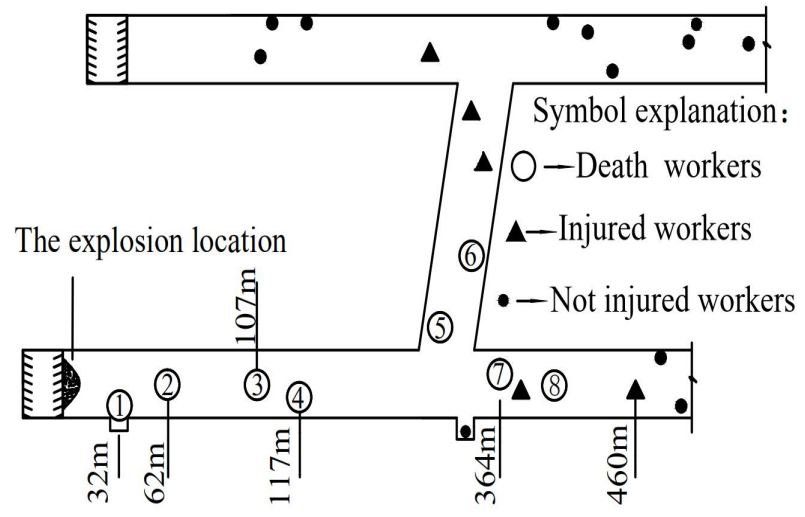

Fig. 4. Schematic of the explosion site

\subsection{Calculation of the blast wave}

As confirmed by the investigation, no coal seam was exposed in the accident section, and no gas emission was found in the monitoring record of the construction. Therefore, the possibility of gas explosion was ruled out at the accident site. According to the investigation and evidence collection, a detonating cord with a length of approximately $14000 \mathrm{~m}$ and a detonating tube with a length of approximately $4000 \mathrm{~m}$ were stacked near the construction working face. The explosive energy of the detonating cord and tube is equivalent to that of approximately $200 \mathrm{~kg}$ of TNT.

The blast wave had a high propagation velocity. The friction resistance, viscosity, and heat transfer of the tunnel contact surface had minimal effect on the shock wave itself. The changes in the physical quantity of the shock wave front mainly exhibited as cylindrical and plane waves. The nearest section of the explosion point generated cylindrical wave. In turn, this cylindrical wave gradually attenuated to plane wave as the energy dissipated in the propagation. Then, it attenuated to sound wave when the distance reached a certain value. The constraints of shock wave reflection theory and tunnel boundary conditions [19] caused the shock wave front to rapidly change from cylindrical wave with unbalanced energy distribution to a plane wave with balanced energy distribution [20]. Therefore, the shock wave in the tunnel mainly propagated in the form of plane wave. The empirical calculation and the simulation were based on the plane wave model.

This accident equaled to the explosion caused by an explosive equivalent to $200 \mathrm{~kg}$ of TNT, which exploded near the working surface. The blast wave spread through the air in the tunnel. Many studies have shown that the damage is mainly caused by the shock wave through overpressure factors. The maximum pressure beyond the pressure value around the object was called peak overpressure, which was denoted as $\Delta P$. Following the planar shock wave theory in the air, the overpressure in its propagation path can be calculated using the following empirical formula [21]:

$$
\Delta P=7.8 \frac{\varepsilon}{r}+38 \sqrt{\frac{\varepsilon}{r}},
$$

where $\varepsilon$ is the energy density of planar shock wave, $\mathrm{J} / \mathrm{cm}^{2}$, which is a one-direction propagation in the tunnel equal to

$$
\begin{aligned}
& \varepsilon=Q_{T} Q_{C T} / S . \\
& Q_{T} \text {-TNT load; } Q_{T}=200 \mathrm{~kg} . \\
& Q_{C T} \text {-Explosion heat of TNT; } Q_{C T}=4225.8 \mathrm{~kJ} / \mathrm{kg} .
\end{aligned}
$$

S-Tunnel section; $S=4.325 \times 10^{5} \mathrm{~cm}^{2}$.

$r$-Distance from the center of the explosion; $\mathrm{m}$.

\subsection{Numerical simulation}

The explosion accident was simulated and analyzed by using finite element analysis software. The calculation was conducted by taking the example of the explosion of a 200 $\mathrm{kg}$ spherical TNT cartridge in the air medium of a tunnel. The tunnel model was established according to the actual situation. The area within $450 \mathrm{~m}$ from the explosion point was selected as the main research area. The section of the tunnel model had a horseshoe shape with width and height of 7 and $8 \mathrm{~m}$, respectively, and a cross section area of 54 $m^{2}$. The regular hexahedron elements were used to divide the grid, and the side length of the grid was $20 \mathrm{~cm}$. Tunnel surrounding rock was not taken as the research object. Therefore, it was assumed as a rigid boundary.

At present, many mature state equations of detonation products are available. Among these equations, $J W L$ state equation can accurately describe the expansion driving process of detonation products. Therefore, JWL equation was used as the state equation of detonation products [22]:

$$
P=A\left(1-\frac{\omega}{R_{1} V}\right) e^{-R_{1} V}+B\left(1-\frac{\omega}{R_{2} V}\right) e^{-R_{2} V}+\frac{\omega E}{V}
$$

Where,

$A, B, R_{1}, R_{2}$ and $\omega$ are all state equations of $J W L$. For TNT, $A=3.712 \mathrm{Mbar}, B=3.23 \times 10^{-2} \mathrm{Mbar}, R_{1}=4.15, R_{2}=0.95$, and $\omega=0.30$.

The shock wave from air explosion generated the pressure surge after wave, thereby resulting in difficulties in solving the differential equation. Therefore, the finite 
element analysis software with artificial volume viscosity was used to change the strong discontinuity surface of the shock wave into a sharp change of physical quantity in a narrow area [23], thereby guaranteeing continuity within the area.

The calculation presented obvious detonation phenomenon that appeared within $50 \mathrm{~m}$, and the detonation wave rapidly propagated. The wave head pressure reached up to $700 \mathrm{kPa}$. Beyond $50 \mathrm{~m}$ from the explosion point, the detonation wave gradually attenuated into a shock wave with the peak pressure exponentially decreasing with the increase in propagation distance. The peak pressure of shock wave at 100,200 , and $300 \mathrm{~m}$ was approximately 115,80 , and $70 \mathrm{kPa}$ respectively. The peak pressure in the intersection of the through-tunnel and explosion tunnel was approximately 52 $\mathrm{kPa}$. The maximum pressure in the through-tunnel was approximately $43 \mathrm{kPa}$, and the peak pressure at $400 \mathrm{~m}$ of the main explosion tunnel was approximately $42 \mathrm{kPa}$ due to the shock wave shunt.

\subsection{Calculation model of the thermal effect of explosionx} The energy instantaneously released from explosive explosion was in the form of shock wave and thermal radiation. According to the explosion efficiency, the fireball generated by explosion in unrestrained open environment was generally of short duration, and the thermal effect was not evident. In this case, shock wave was the main factor that caused casualty. When the explosion occurred in a confined space, such as a tunnel, the release efficiency of the explosive energy was greatly improved, and the duration of thermal radiation of explosive fireball significantly improved, thereby sharply increasing the tunnel temperature. The analysis of casualties caused by shock wave in the accident was basically consistent with facts, and the thermal radiation of explosion was also the main factor that caused casualties in the accident. Regarding the propagation and absorption of thermal radiation, Stephen Boltzmann reported that the thermal radiation of any object was proportional to the fourth power of temperature. For this accident, the air temperature in the tunnel was the main parameter used to evaluate the thermal radiation effect of explosion.

The air before the shock wave was assumed to be under the standard atmospheric state: $P_{0}=101 \mathrm{kPa}, \rho_{0}=1.225 \mathrm{~kg} / \mathrm{m}^{3}$ and $T_{0}=273.15 \mathrm{~K}$. Then, medium temperature relation before and after shock wave in multi-gas can be expressed as [24]:

$$
\frac{T}{T_{0}}=1+\frac{2(\gamma-1)}{(\gamma+1)^{2}}\left(M_{0}^{2}-1\right)\left(\gamma+\frac{1}{M_{0}^{2}}\right)
$$

$T$ - Peak value of explosion temperature, $\mathrm{K}$.

$T_{0}$-Standard air temperature, $\mathrm{K}$.

$\gamma$-Shock wave coefficient [25], its value in air is 1.4 .

$M_{0}$-Shock Mach number,

$$
M_{0}^{2}=\frac{1}{2 \gamma}\left[(\gamma-1)+(\gamma+1) \frac{P}{P_{0}}\right] .
$$

$P$ - pressure after shock wave, $\mathrm{kPa}$; and $P_{0}$ - pressure before shock wave, $\mathrm{kPa}$.

\subsection{Harmful explosive gas}

The casualties caused by shock wave and the thermal effect in the accident were analyzed. Nevertheless, the harmful gas generated from the explosion accident cannot be ignored, especially in confined space. The detonating cable that exploded on-site contained $182 \mathrm{~kg}$ of hexogen. Hexogen $\left(\mathrm{C}_{3} \mathrm{H}_{6} \mathrm{O}_{6} \mathrm{~N}_{6}\right)$ is a single-component high explosive with an oxygen balance value of -0.216 . It is also a typical negative oxygen balance explosive. According to the maximum heat release principle, the approximate explosion reaction equation is expressed as follows [26]:

$$
\mathrm{C}_{3} \mathrm{H}_{6} \mathrm{O}_{6} \mathrm{~N}_{6}=3 \mathrm{CO}+3 \mathrm{H}_{2} \mathrm{O}+3 \mathrm{~N}_{2}
$$

The specific volume of hexogen is $908 \mathrm{~L} / \mathrm{kg}$, and the total production amount of explosive gas is approximately: $908 \mathrm{~L} / \mathrm{kg} \times 182 \mathrm{~kg}=165256 \mathrm{~L}=165.3 \mathrm{~m}^{3}$. CO accounted for $1 / 3$ of the explosive gas, which was approximately $35.1 \mathrm{~m}^{3}$. If the uniform diffusion was considered, then the $\mathrm{CO}$ concentration was approximately $0.201 \%$ within the range of $450 \mathrm{~m}$ from the tunneling working face, including the through-tunnel. However, the maximum allowable concentration of toxic gas in underground blasting operations was $0.0024 \%$. Thus, the CO concentration in the tunnel was approximately 85 times of the stipulated level, thereby seriously exceeding the limitation. Therefore, the workers in the aforementioned range were likely to suffocate or even die from CO poisoning at the time of the explosion. The safe distance of harmful explosive gas can be calculated using the formula of gas diffusion range in mine blasting [27]:

$$
R=\frac{0.833 k Q b \alpha+\sum V}{S},
$$

where,

$k$-Ventilation effect coefficient; without ventilation $k=1$.

$Q$ - Explosive amount, $\mathrm{kg}$.

$b$ - poisonous gas produced per $\mathrm{Kg}$ explosives (equivalence to $\mathrm{CO}), b=0.9 \mathrm{~m}^{3} / \mathrm{kg}$.

$\alpha$ - Coefficient related to contact surface of caving area, $\alpha=1.0 ;$ and

$\sum V$ - Total volume of the roadway that the blasting smoke passes through, $m^{3}$, here $\sum V=17725 m^{3}$.

\section{Result Analysis and Discussion}

\subsection{Analysis of overpressure propagation characteristics of shock wave in tunnel}

The overpressure values of the blast wave at different distances from the detonation source point were calculated according to the overpressure empirical formula on the propagation path. The calculation results are shown in Figure 5.

Figure 5 shows that the overpressure of the shock wave exhibited a linear attenuation characteristic in the propagation range of $0-30 \mathrm{~m}$. The absolute value of the linear slope was large, indicating that the attenuation is extremely fast in this range. The overpressure of the whole segment was larger than $900 \mathrm{kPa}$. The overpressure of the shock wave showed an exponential attenuation characteristic during its propagation in the range of $30-200 \mathrm{~m}$, and the overpressure ranged from $900-200 \mathrm{kPa}$. The shock wave overpressure presented a linear attenuation characteristic in the propagation range of $200-400 \mathrm{~m}$. The absolute value of 
the linear slope was small. In this segment, the overpressure attenuation gradually became stable with the overpressure range of $200-100 \mathrm{kPa}$.

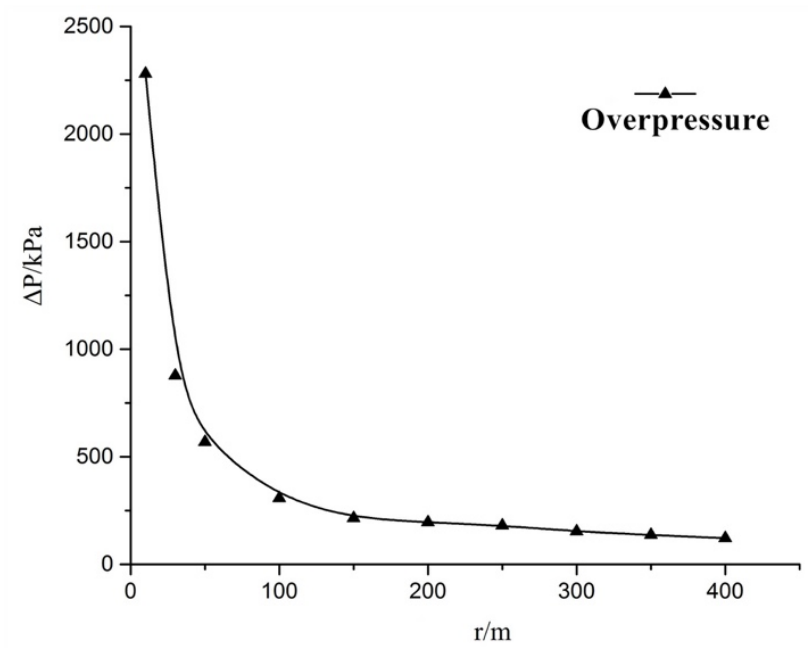

Fig. 5. Overpressure $(\Delta P)$-distance $(r)$ relationship curve calculated using the empirical formula

The numerically simulated overpressure-distance relationship curve was obtained by collecting the data of numerical calculation results at different points. The result is shown in Figure 6.

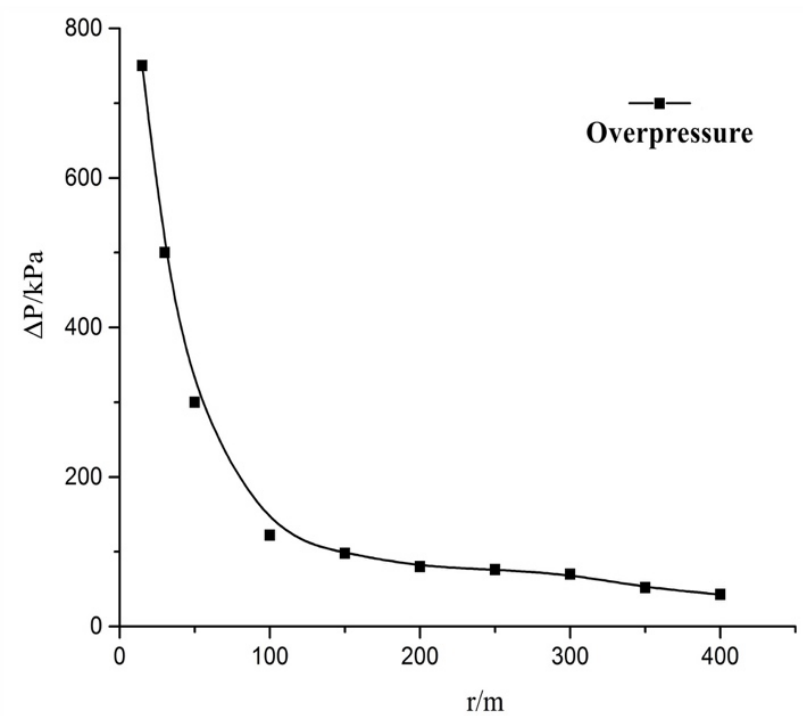

Fig. 6. Numerically simulated overpressure-distance relationship curve

The simulated overpressure-distance relationship curve (Figure 6) and the calculated relationship curve from empirical formula (Figure 5) were compared and analyzed. The simulation result was smaller than that from the empirical formula. Such deviation originated from the mutual restriction of the calculation accuracy and the computing hardware resources because the spatial scale of the whole tunnel was large. Space meshing cannot reach fine division due to the limitation of hardware resource. Thus, addressing the discrete element with limited resolution was difficult because of the high frequency component of shock wave, resulting in the fast shock wave attenuation in the propagation and the large deviation of the simulated shock wave strength from the results based on the empirical formula in the large distance range. Therefore, the two aforementioned calculations results needed to be integrated. To make the peak pressure of shock wave closer to the actual situation, the curve of the mean overpressure-distance relationship curve was achieved by taking the average value of the two calculation results. The curve is shown in Figure 7.

In Figure 7, the shock wave propagated in the form of detonation wave within $100 \mathrm{~m}$ from the explosion point in the tunnel, and the overpressure was serious. In the distance of $100-400 \mathrm{~m}$, the overpressure range was $240-90 \mathrm{kPa}$. The human casualties were concentrated in the propagation path of the shock wave within $400 \mathrm{~m}$ from the explosion point. The corresponding accident analysis can be achieved by combining the schematic of the explosion site in Figure 4 and the table of the human and building damage caused by the shock wave overpressure in Table 1 [28].

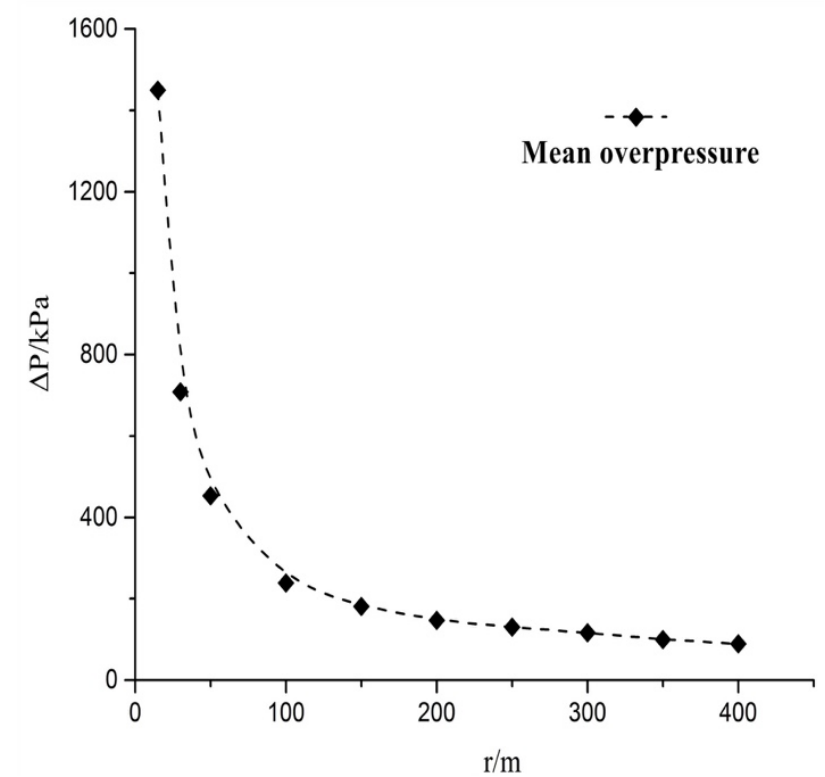

Fig. 7. Mean overpressure-distance relationship curve

Table. 1. Damage to personnel and building caused by shock wave overpressure

\begin{tabular}{|c|c|c|}
\hline $\begin{array}{c}\text { Shock wave } \\
\text { overpressure } \\
\Delta P / k P a\end{array}$ & Damage to personnel & Damage to building \\
\hline$\leq 30$ & Mild impairment & $\begin{array}{l}\text { Windows and doors } \\
\text { were damaged, the } \\
\text { brick wall obtained } \\
\text { small cracks. }\end{array}$ \\
\hline $30-50$ & $\begin{array}{l}\text { Moderate } \\
\text { impairment, } \\
\text { fracture }\end{array}$ & $\begin{array}{l}\text { The brick wall } \\
\text { obtained large } \\
\text { cracks, and tiles fell } \\
\text { off. }\end{array}$ \\
\hline $50-98$ & $\begin{array}{l}\text { Severe visceral } \\
\text { impairment or } \\
\text { death }\end{array}$ & $\begin{array}{l}\text { The building frame } \\
\text { was loose, and the } \\
\text { brick walls partially } \\
\text { collapsed. }\end{array}$ \\
\hline$\geq 98$ & Death & $\begin{array}{l}\text { The buildings } \\
\text { collapsed. }\end{array}$ \\
\hline
\end{tabular}

Figure 4 shows that six people died inside the main tunnel within $400 \mathrm{~m}$, and two were seriously injured beyond $400 \mathrm{~m}$. Two people died and three were seriously injured inside the through-tunnel. This comprehensive analysis suggests that the overpressure within $400 \mathrm{~m}$ of the main tunnel in the explosion accident is greater than $90 \mathrm{kPa}$. Table 1 shows the damage when the overpressure reached $90 \mathrm{kPa}$. 
In such case, staff was likely to die because of shock wave overpressure. Thus, the deaths within $400 \mathrm{~m}$ of the main tunnel were mainly caused by the high shock wave overpressure. The average calculation results were consistent with the actual accident situation. However, due to shock wave shunt, energy collapsed in the through-tunnel, and the maximum overpressure was approximately $43 \mathrm{kPa}$, which was impossible to directly cause death. Therefore, other factors should be considered to analyze the casualties in the through-tunnel.

\subsection{Analysis of the impact of thermal effect and harmful gas from explosion}

The air temperature at different distances from the detonation point can be calculated by the medium temperature relation before and after shock wave in combination with the pressure data after the shock wave in Figure 7. The calculation results are shown in Figure 8.

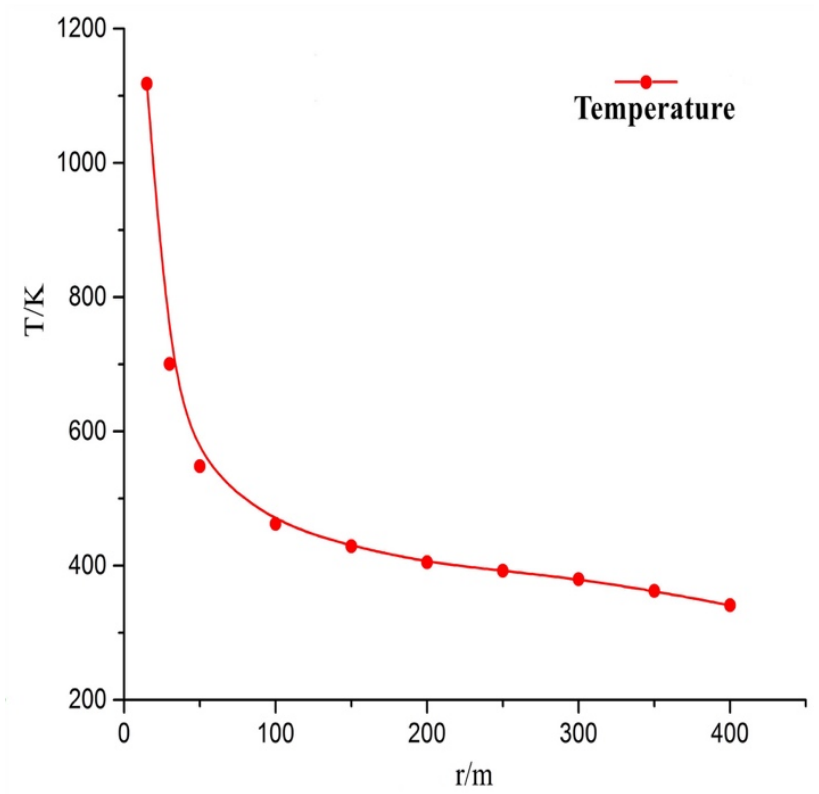

Fig. 8. Temperature $(T)$-distance $(r)$ relationship curve

The temperature exceeded $380 \mathrm{~K}$ within $300 \mathrm{~m}$ of the main tunnel; the temperature in its intersection with throughtunnel can reach $360 \mathrm{~K}$. Pieyersen et al. found that thermal radiation injury caused skin burns. The temperature in the main tunnel exceeded the range tolerable for people, and the temperature in the through-tunnel was high enough to cause severe burns or even death. The temperature attenuation in the main tunnel gradually stabilized beyond $400 \mathrm{~m}$. The overall temperature was under $330 \mathrm{~K}$, thereby hardly causing severe burns or death. This analysis implies that the casualties in the through-tunnel were directly related to the thermal radiation effect of explosion.

The relevant parameters of harmful gas were included in the gas diffusion range formula. As a result, $\mathrm{R}=411.5 \mathrm{~m}$. Therefore, the shock wave and harmful gas generated by the explosion still had great lethality at a distance of $400 \mathrm{~m}$ from the explosion source. In Figure 4, the location of casualties at the scene of the accident was within this range. The theoretical analysis was basically consistent with the casualties at the scene.

In this tunnel explosion accident, the theoretical analysis basically agreed with the actual situation. Therefore, the specific dangerous range of casualties in tunnel explosion under different explosive dosages can be deduced on the basis of the aforementioned theory, which provides reference for safety departments in practical engineering. The dangerous range of casualties refers to the maximum distance from the explosives on the working face to the location of casualties. Taking TNT as an example, the minimum shock wave overpressure that caused casualties was set at $90 \mathrm{kPa}$, the maximum allowable concentration of toxic gas was $0.0024 \%$, and the thermal radiation temperature that caused serious injury was set at $360 \mathrm{~K}$. When a shock wave overpressure, a toxic gas concentration, or a thermal radiation temperature in a certain part of the tunnel exceed the set range, that part was then considered an explosion risk area, in which casualties are likely to occur.

The amounts of explosives stacked on the tunnel working face were assumed to be 5, 10, 20, 30, 50, 100, 150, and $200 \mathrm{~kg}$. The tunnel section area was assumed to be $55 \mathrm{~m}^{2}$. The dangerous area of casualties that corresponds to different explosive dosage can be determined by using the theoretical calculation, numerical simulation, and comprehensive analysis of the impact of thermal effect and harmful gas. The results are shown in Figure 9.

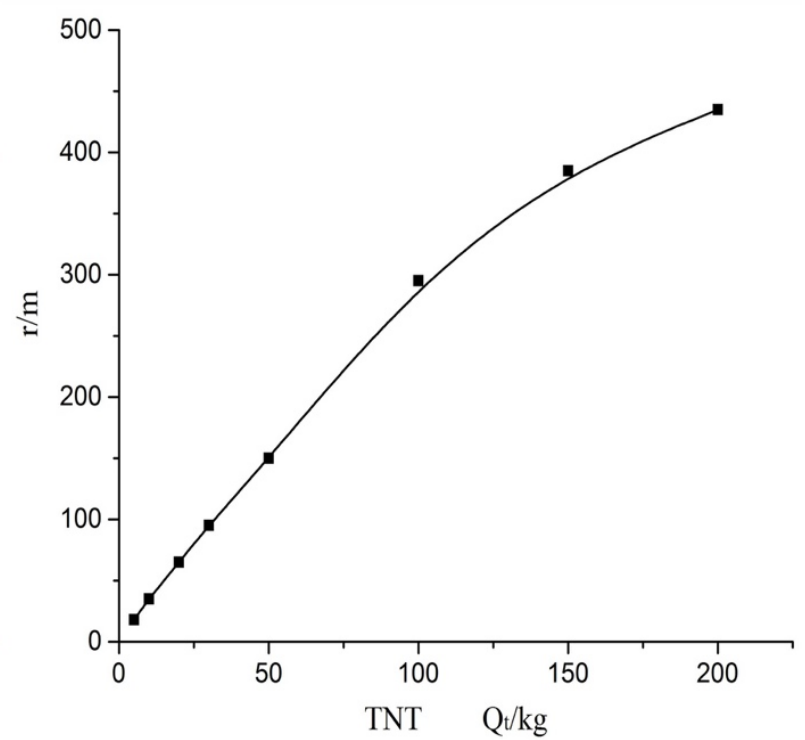

Fig. 9. Relationship curve between explosive dosage (TNT) and dangerous range of casualties

In Figure 9, the dangerous range of casualties that corresponds to the dosages of $5 \mathrm{~kg}$ and $10 \mathrm{~kg}$ TNT are approximately $18 \mathrm{~m}$ and $35 \mathrm{~m}$, respectively. Similarly, the dangerous range of casualties that corresponds to $20,30,50$, 100,150 , and $200 \mathrm{~kg}$ of TNT dosages was $65,95,150,295$, 385 , and $440 \mathrm{~m}$, respectively. In a dosage within $100 \mathrm{~kg}$, the explosive amount was approximately linearly correlated with the dangerous range. When the dosage is in the range of $100-200 \mathrm{~kg}$, the slope of explosive dose-dangerous range curve gradually decreases, and the curve is approximate to a logarithmic function. In Figure 9, the dangerous range of casualties that corresponds to different dosages of explosives can be determined by taking the explosives stacked near the tunnel working face as an example. The construction personnel in this range should keep their concentration high. Other staff in this area should be reduced as much as possible. Warning signs should be placed at the boundary of the dangerous area to restrict the entry of unauthorized personnel. 


\section{Conclusions}

To explore the characteristics of the explosion accidents in tunnel and reveal the properties of explosion products and their harmful impact, this study started from practical engineering example. Then, this study analyzed the shock wave characteristics and the effects of thermal energy and the harmful gas. Finally, this study determined the dangerous working area by combining the theoretical analysis and numerical calculation method. In the end, the following conclusions can be drawn:

(1) A large number of detonating fuses, equivalent to approximately $200 \mathrm{~kg}$ of TNT, exploded in the semi-closed tunnel. The explosion produced shock wave, thermal radiation, and harmful gas with the impact scope that exceeded $400 \mathrm{~m}$, thereby resulting in huge damage.

(2) The dangerous range of casualties that corresponded to different dosages of explosives was obtained. The construction personnel in this range should have high concentration, and other staff should be reduced in the area as much as possible.

(3) The main causes of this accident included illegal operation, randomly stacked detonating fuses at the scene of the accident without any awareness of prevention, disorganized management, large management loopholes appeared in the process of implementation, weak safety awareness of construction personnel, and lack sufficient understanding of the dangerous nature of explosive products. Moreover, most workers simply believed that "only explosives will explode, while the detonating cord does not."

This study provided insight into the law of the hazard impact degree of tunnel explosion by combining engineering examples with theoretical analysis. This study also deduced the specific dangerous range of explosion casualties under different dosages of explosives in the tunnel via theoretical calculation, which provided reference for the safety department in practical engineering. A field simulation test, which will be modified in combination with this study, will be performed in future study, due to the lack of actual explosion data of sudden accidents. On this basis, the law of safety accident in tunnel explosion will be accurately understood, and the engineering safety level will be improved.

\section{Acknowledgements}

This work was supported by Nanhu Scholars Program for Young Scholars of Xinyang Normal University.

This is an Open Access article distributed under the terms of the Creative Commons Attribution License

\section{References}

1. Hongan, C., "Investigation and Analysis on a Blasting Accident". Blasting, 20(3), 2003, pp.88-90.

2. Jiping, S., "The causes and lessons of 2.22 gas explosion disaster at Tunlan Coal Mine".Journal of China Coal Society, 35(1), 2010, pp. 72-75.

3. Qiushi, Y., Chenxu, L., "Study on dynamic response of subway tunnel subjected to inter-explosion loading". Concrete, 5(3), 2019, pp.7-10.

4. Zhongxian, L., Xin, J., Jianwen, Liang., "IBIEM Modeling of the Elastic Dynamics Response on a Lined Tunnel Under Blast Loading in Saturated Poroelastic Half-space". Chinese Journal of Solid Mechanics, 39(5), 2018, pp. 492-503.

5. Le, X., Zhiyong, Y., Huanqiu, L., "Dynamic Response of Rectangular Tunnel Lining Structure under Explosion”. Blasting, 35(4), 2018, pp. 40-46.

6. Zhipeng, L., Shunchuan, W., Qiong, Y., "Numerical analysis on the tunnel gas explosion and study on the method for determining the type of burst source". Journal of Vibration and Shock, 37(14), 2018, pp. 94-101.

7. Zhipeng, L., Shunchuan, W., Qiong, Y., "Numerical simulation and mechanism analysis of tunnel lining structure damage subjected to severe gas explosion". Journal of China Coal Society,43(s1), 2018, pp. 167-177.

8. Desen, K., Qinghui, M., Weiwei, Z., "Shock responses of a metro tunnel subjected to explosive loads". Journal of Vibration and Shock, 31(12), 2012, pp. 68-72.

9. Desen, K., Qinghui, M., Mingchen, S., "The Dissemination Rule of Blasting Shock-wave in Subway Tunnel". Chinese Journal of Underground Space and Engineering,8(1), 2012, pp. 48-55.

10. Casal, J., Sallam, J. M., "Using liquid superheating energy for a quick estimation of overpressure in BLEVEs and similar explosions". Journal of Hazardous Materials,137(3), 2006, pp.1321-1327.

11. Genova, B., Silvestrini, M., Trujillo, L. F. J., "Evaluation of the blast-wave overpressure and fragments initial velocity for a BLEVE event via empirical correlations derived by a simplified model of released energy". Journal of Loss Prevention in the Process Industries, 21(1), 2008, pp. 110-117.

12. Benselama, A. M., William, L. M. J., Monnoyer, F., “A numerical study of the evolution of the blast wave shape in tunnels". Journal of Hazardous Materials, 181(3), 2010, pp. 609-616.
13. Uystepruyst, D., Monnoyer, F., "A numerical study of the evolution of the blast wave shape in rectangular tunnels". Journal of Loss Prevention in the Process Industries, 34(1), 2015, pp. 225-231.

14. Pennetier, O., William, L. M., Langlet, A., "Numerical and reducedscale experimental investigation of blast wave shape in underground transportation infrastructure". Process Safety and Environmental Protection, 94(1), 2015, pp. 96-104.

15. Smith, P. D., Vismeg, P., Teo, L. C., "Blast wave transmission along rough-walled tunnels". International Journal of Impact Engineering, 21(6), 1998, pp. 419-432.

16. Xiaoping, W., Minggao, Y., Wentao, J., et al., "Methane-air explosion characteristics with different obstacle configurations". International Journal of Mining Science and Technology, 25(2), 2015, pp. 213-218.

17. Syrunin, M. A., Fedorenko, A. G., Ivanov, A. G., "Reaction and Strength of a Fiberglass Container under Internal Explosive Loading". Combustion Explosion and Shock Waves, 38(3), 2002, pp. 365-373.

18. Rao, L., Wu, Y., "Discuss our country engineering construction safety management based on Luliang mountains tunnel explosion accident". Safety, 8(1), 2013, pp. 3-4.

19. Yunliang, G., Zonglin, J., "On transition criterion of Mach stem deformation for Mach reflections of pseudosteady strong shock waves". Explosion and shock waves, 29(02), 2009, pp. 143-148.

20. Zhiming, Q., Xinquan, Z., Haiyan, W., "Overpressure attenuation of shock wave during gas explosion". Journal of China coal society,33(4), 2008, pp. 410-414.

21. Jingbo, L., Qiushi, Y., Jun, W., "The analysis of blast wave propagation inside tunnels". Vibration and shock, 28(6), 2009, pp. 8-11.

22. Xianzhen, J., Yiting, H., Mingrong, D., "Equivalent mass method of underwater explosion shock wave simulation based on ANSYS/LSDYNA". Journal of projectiles, rockets, missiles and guidance, 28(3), 2008, pp. 159-162.

23. Xinghua, D., Yang, G., "Viscoelastic artificial boundary used in the finite element analysis". Low temperature architecture technology, 34(1), 2012, pp.76-78.

24. Wenhui, T., "Shock wave physics". Beijing: Science press, China, 2011, pp. 108-115.

25. Weixin, L., "One-dimensional nonsteady flow and shock waves". Beijing: National defence industry press, China, 2003, pp. 47-50. 
Dong Yan, Qiong Wu, Tengyu Li and Yinyin Ren/Journal of Engineering Science and Technology Review 12 (4) (2019) 152 - 159

26. Yuanjie, S., "Explosive subject generality". Beijing: Chemical industry press, China, 2011, pp. 18-26.

27. Yajun, C., "Mine blasting and security technology".Beijing: China Meteorological Press, China, 2011, pp. 37-50.

28. Zhimin, F., Jinyin, H., Na, Z., "Quantitative analysis for consequence of explosion shock wave". Fire science and technology, 28(06), 2009, pp. 390-395. 